\title{
Potential impact of climate change on fire risk in the Mediterranean area
}

\author{
M. Moriondo ${ }^{1, *}$, P. Good ${ }^{2}$, R. Durao ${ }^{3}$, M. Bindi ${ }^{1}$, C. Giannakopoulos ${ }^{2}$, J. Corte-Real ${ }^{3}$ \\ ${ }^{1}$ Department of Agronomy and Land Management, University of Florence, Piazzale delle Cascine 18, 50144 Florence, Italy \\ ${ }^{2}$ Institute for Environmental Research and Sustainable Development, National Observatory of Athens, PO Box 20048, \\ Thissio, 11810 Athens, Greece \\ ${ }^{3}$ Instituto de Ciência Aplicada e Tecnologia, Universidade de Lisboa, 1749-016 Lisboa, Portugal
}

\begin{abstract}
In this study, output of the Hadley Centre Regional Circulation Model (RCM) (HadRM3P, $0.44^{\circ} \times 0.44^{\circ}$ resolution) was used as input to the Canadian Forest Fire Weather Index (FWI) for the present and 2 future IPCC climate scenarios (Special Report on Emissions Scenarios [SRES], A2 and B2 scenarios). The aim was to investigate the effects of climate change on fire risk (number of days with fire risk, length of fire risk season, etc.) for the EU Mediterranean countries. Results indicated a general increase in fire risk in both future scenarios over the whole study area. The increase in fire risk was mainly due to 3 components: (1) increase in the number of years with fire risk; (2) increase in the length of the season with fire risk ( ) increase of extreme events (e.g. total number of days with FWI $>45$ and episodes with FWI $>45$ for 7 consecutive days) during the fire season. As expected, A2 scenario showed a greater increase in risk than B2 scenario. These general increases in fire risk may have a very strong impact in areas where forest land cover is high (e.g. the Alps region in Italy, the Pyrenees in Spain and mountains of the Balkan region).
\end{abstract}

KEY WORDS: Climate change $\cdot$ Forest fire $\cdot$ RCMs $\cdot$ Mediterranean basin $\cdot$ A2 and B2 IPCC-scenarios

\section{INTRODUCTION}

Mediterranean forests are regularly subjected to a large number of fires. About 50000 fires destroy from $700 \times 10^{3}$ to $1000 \times 10^{3}$ ha of Mediterranean forests annually, causing enormous economic and ecological destruction (Velez 1997). In particular, the data collected reveal that, according to the average burnt area per fire, Greece has the most severe forest fire problems among the European Union countries. It has been estimated that the average burned area per fire was 39.4, 28.5, 19.7 and 15.3 ha in Greece, Spain, Italy and Portugal, respectively (Dimitrakopoulos 1994). The destruction of forests is of great concern, as this has many side effects e.g. floods, soil erosion and consequent loss of fertility (Court-Picon et al. 2004, Iliadis 2004). Furthermore, it has been demonstrated that forest fires play a fundamental role in determining the net carbon balance of the forest (Kurz et al. 1995). Thus, they may affect greenhouse gas emissions with consequent feedback on climate change (Flannigan et al. 2001).

The predicted changes in climate for this century are expected to be accompanied by changes in regional fire regimes as confirmed by paleontological evidence (Clark 1990) and correlation data from the last century (Beer et al. 1988). Forest fires, similar to other ecosystem processes, are highly sensitive to climate change because fire behaviour responds immediately to fuel moisture, which is affected by precipitation, relative humidity, air temperature and wind speed. The projected increase in temperature will increase fuel dryness and reduce relative humidity, and this effect will become more severe in those regions where rainfall decreases (Howden et al. 1999). Accordingly, increases in climate extreme events are expected to have a great impact on fire risk.

Many attempts have been made to quantify potential impact of climate change on fire risks (Torn \& Fried 
1992, Stocks et al. 1998, Flannigan et al. 2000, Williams et al. 2001, Mouillot et al. 2002, Brown et al. 2004). In these studies, climate data obtained from General Circulation Models (GCM) were used directly as input variables of fire danger indices, or indirectly by calculating 'change factors', i.e. adding differences between present and future scenario of GCM gridboxes to the baseline climatology (e.g. Arnell 2003). Results of these simulations confirmed the expected increase in fire risk, burned area and frequency of fires. However, the low spatial resolution of GCM grid boxes $\left(\sim 2.5^{\circ}\right.$ Lat. $\times$ $\sim 3.5^{\circ}$ Long.) and the low capability of GCMs to reproduce climate variability (e.g. convection scheme used to describe precipitation or land-surface scheme for maximum and minimum temperature) (Kharin \& Zwiers 2000) made these analyses unsuitable for local impact studies such as those on forest fires, especially in areas like the Mediterranean with a complex morphology (Giorgi 1990).

To fill this gap, regional circulation models (RCMs) were developed as a form of dynamical downscaling. In these models the GCM outputs are used to provide boundary conditions to other models running at a higher resolution, providing a higher spatial resolution of local topography $\left(0.5^{\circ} \times 0.5^{\circ}\right.$ resolution $)$ and a more realistic simulation of fine scale atmospheric features. Recent studies have demonstrated the capacity of RCMs to reproduce fine-scale features of different regional climates (Hulme et al. 2002), and this makes RCMs more reliable as tools for climate change impact studies in general, and fire risk assessments in particular.

Following these considerations, the aim of this study was to use the Hadley Centre RCM outputs as input to the Canadian Forest Fire Weather Index (FWI), to investigate possible changes in fire risk (number of days with fire risk, length of fire risk season, etc.) in the Mediterranean basin under future climate IPCC scenarios (A2 and B2).

\section{MATERIALS AND METHODS}

\subsection{Regional Circulation Model}

The RCM developed by the Hadley Center (HadRM3) has a spatial resolution of $0.44^{\circ}$ Lat. $\times 0.44^{\circ}$ Long. and operates using a dynamical downscaling procedure. This takes boundary conditions from a coarser resolution global model and provides a higher spatial resolution of local topography and more realistic simulations of fine-scale atmospheric features. More specifically, the outputs of the coupled oceanatmosphere HadCM3 (2.5 ${ }^{\circ}$ Lat. $\times 3.75^{\circ}$ Long.) experiments provide the boundary conditions to drive a high resolution $(\sim 120 \mathrm{~km})$ model of the global atmosphere
(HadAM3H), and the outputs from this model in turn provide the boundary conditions to drive HadRM3. HadCM3 model runs are forced between 1860-1990 by observed changes in greenhouses gases and aerosols to simulate changes in climate to date. From 1990 onwards, a number of scenarios of future changes in greenhouse gases and aerosols are used (IPCC 2000).

In this study, 2 time-slices (1961-1990 and 2071-2100) were considered to represent present and future climate, respectively. Further, 2 emission scenarios were selected among those proposed by the Special Report on Emissions Scenarios (SRES) (IPCC 2000): (1) scenario A2, characterised by medium-high greenhouse gas emissions; and (2) scenario B2, characterised by medium-low greenhouse gas emissions.

\subsection{Fire Weather Index}

The FWI is a daily meteorological-based index designed in Canada and used worldwide to estimate fire danger in a generalized fuel type. FWI consists of 6 standard components each measuring a different aspect of fire danger (Van Wagner 1987).

The first 3 components are fuel moisture codes that simulate daily changes in the moisture contents of 3 classes of forest fuel with different drying rates. The Fine Fuel Moisture Code (FFMC) is a numerical rating of the fuel moisture in surface litter and light dead fuel, and is used as an indicator of fire ignition potential. The Duff Moisture Code (DMC) is a numerical rating of the fuel moisture in shallow to medium, loosely compacted duff at a depth of 10 to $20 \mathrm{~cm}$, and in medium weight surface fuels. The Drought Code (DC) is a numerical rating of the fuel moisture in deep, compact organic layers and in heavier surface fuels, and is used as an indicator of smouldering potential.

The other 3 components are related to the fire behaviour representing the rate of spread, fuel weight consumed and fire intensity. The Initial Spread Index (ISI) is a numerical rating of a fire's rate of spread after ignition. The Buildup Index (BUI) is a numerical rating of the total amount of fuel available for consumption. The FWI is a numerical rating of a fire's intensity, and is used to estimate the difficulty of fire control.

The system depends solely on weather readings taken each day at noon: temperature, relative humidity, wind speed and rainfall. The current month must also be specified. In this work, RCM daily outputs of maximum temperature (Tmax), relative humidity $(\mathrm{RH})$, wind speed at $10 \mathrm{~m}$ above ground (W), and total rainfall (R) were used as input variables to the FWI system.

The FWI system was developed for Canadian forests but it also found a wide application in other countries and environments such as Mexico, south-east Asia, 
Florida, Argentina etc. For the Mediterranean basin, several studies showed that the FWI system and its components were well suited to the estimation of fire risk for the region (Sol 1999, Viegas et al. 1999, Viegas et al. 2001, Aguado et al. 2003). In particular, in a comparative study of various methods of fire danger evaluation in southern Europe, Viegas et al. (1999) found that the FWI system components showed the best overall correlation with fire activity in southern Portugal, Spain, France and Italy, even though the vegetation and dry Mediterranean climate are markedly different from that in Canada. Moreover, FWI is currently one of the fire risk indices used by the Joint Research Centre (JRC), Ispra Establishment, to produce fire map risk at the European Union level (see http://effis.jrc.it). The success of this system is due both to the simplicity of its calculation procedures and to the simulation of moisture of a generalized fuel type that has been successfully applied to model fire potential in a broad range of fuel types (Van Wagner 1975).

Since this work focused on fire danger instead of burned area or number of fires, the complexity of the problem was reduced by making assumptions about numerous societal components of fire, land use and vegetation change. In particular, fire danger is not considered to be influenced by future changes in fire suppression strategy, and land use policy remains unchanged. Moreover, since FWI gave good results when run with a generalized fuel type, no changes have been introduced to the model to take into account modification of vegetation characteristics in response to climate.

\subsection{Forest land cover}

To relate changes in fire risk with the actual forest land cover, a map of the percentage of land covered by forest for the study area (Fig. 1) was extracted from the map $(1 \times 1 \mathrm{~km}$ resolution) provided for the whole of Europe by Schuck et al. (2002, their Fig. 9). In

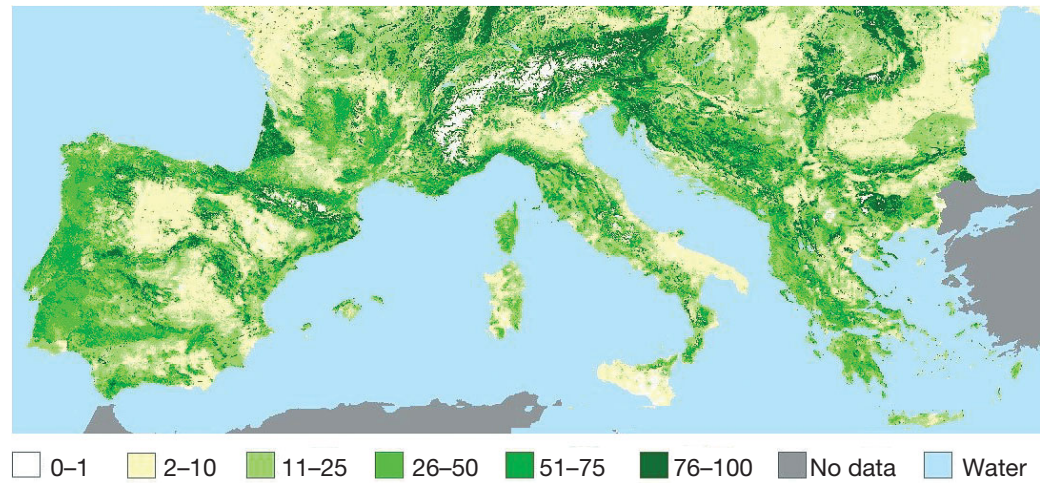

Fig. 1. Percentage of land covered by forest in Europe (Schuck et al. 2002) particular, Schuck et al. (2002) estimated the percentage forest probability for each Advanced Very High Resolution Radiometry (AVHRR) pixel, using COoRdinate INformation on the Environment (CORINE) land use classification as training data to establish the link between different classes and AVHRR spectral response.

\subsection{Fire risk analysis}

Several parameters related to the risk of fire were calculated for present and future climate scenarios (e.g. length of season with fire risk, mean seasonal FWI, number of seasons with fire risk etc.). Concerning the length of the fire season, Wotton \& Flannigan (1993) stated that the critical issue for fire season length determination is to define criteria for the beginning and end of the fire season. Different methodologies were used to define the onset of the fire season. Generally, these were based on a temperature threshold that was exceeded for at least $3 \mathrm{~d}$ (Turner \& Lowson 1978, Simard et al. 1989, Wotton \& Flannigan 1993). Fewer indications were provided to determine the end of fire season. Simard et al. (1989) estimated the end of fire season by the reverse of the criteria used to start it, i.e. 3 consecutive days of maximum temperatures below $7.2^{\circ} \mathrm{C}$. Fire danger class criteria (i.e. days of very high-extreme fire danger index) could also be used to identify fire season start and end dates, since these indices describe the periods with greater likelihood of increased fire activity (given that other factors such as fuel and ignition are considered equal) (Pearce et al. 2005).

In this study, the methods based only on temperature threshold caused a number of 'false alarms' for the beginning and end of fire seasons due to the high variability of maximum temperature during the year. Thus, to avoid 'false alarms' affecting our results, a more robust approach-based directly on daily FWI values - was used. The choice of FWI threshold indicating the fire risk was based on results obtained by Hanson \& Palutikof (2005). On a local scale (Greece and Italy), they found a non-linear relationship between the frequency of forest fires and FWI (Fig. 2). In particular, the rate of the frequency of forest fires was low for FWI $<15$, whereas it increased more rapidly with $15<$ FWI $<45$. For FWI $>45$, the rate of the frequency of forest fires was even higher. Accordingly, FWI $\geq 15$ was used as a threshold to define the beginning and end of a potential fire season over the Mediterranean basin. A 


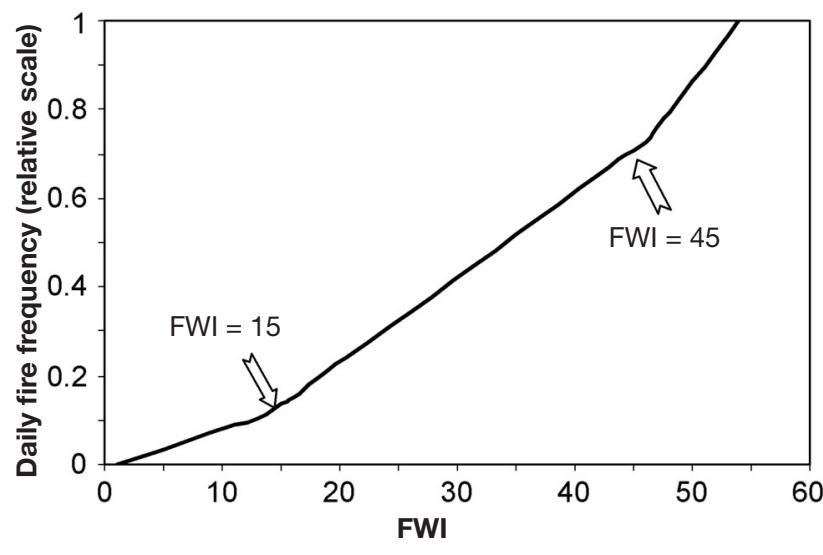

Fig. 2. Relationship between daily fire weather index (FWI) and observed daily frequencies of forest fires lated with dry and hot climate conditions recorded in southern Europe (e.g. Iberian Peninsula and Greece) (Whelan 1995, Mouillot et al. 2002). This ranged, on average, from $170 \mathrm{~d}$ in Spain to $75 \mathrm{~d}$ in the flat areas of France (Table 1). When moving from flat to mountainous areas, the length of fire seasons progressively decreased to $20 \mathrm{~d}$ at high altitude in the Balkan countries (>1500 m) (Table 1$)$. The same pattern was observed for the frequency of fire seasons, with the highest frequency $(\sim 100 \%)$ being observed in the flat areas of southern Europe. This frequency decreased in higher areas, especially in the Balkans, France and Italy, whereas in Greece and the Iberian peninsula high frequencies ( 90\%) were also observed at high altitudes (Table 2).

\subsection{Changes in fire risk}

\subsubsection{Seasonal FWI}

$7 \mathrm{~d}$ was calculated to smooth daily variability of FWI fire season was defined as at least 2 consecutive weeks with FWI > 15 and FWI < 15, respectively.

Using the same thresholds, the seasonal mean of FWI and the number of years with fire risk within the 2 selected time-series (1961-1990 and 2071-2100) were also identified. Further to these mean changes in fire risk, the changes in occurrence of extreme events during the fire season were evaluated. In particular, 3 parameters were selected: (1) the highest FWI value in the fire season; (2) the total number of daily FWI above a threshold during the fire season; and (3) the persistence of high FWI values during the fire season.

The highest annual values of FWI were fitted to the generalized extreme value (GEV) distribution according to the Gumbel model, in order to estimate the return period between events. The total number of days with extreme FWI values, and the persistence of extreme FWI values, were calculated according to results of Hanson \& Palutikof (2005), using thresholds of 45 as daily values of FWI and 7 consecutive days as persistence time.

\section{RESULTS AND DISCUSSION}

\subsection{Thresholds for calculating risk of fire season}

The selected thresholds allowed the reproduction of different characteristics of fire risk (length and frequency of the fire season) across the European-Mediterranean area. The length of the fire seasons was positively corre-
Table 1. Average dates (day of year) of the beginning/end of fire seasons in different Mediterranean zones. Elevation classes - 1: 0-300; 2: 300-600; 3: 600-900; 4: 900-1200; 5: 1200-1500; 6: >1500 m asl

\begin{tabular}{|lrrcccc|}
\hline & 1 & 2 & 3 & 4 & 5 & 6 \\
\hline Balkan & $174 / 276$ & $184 / 274$ & $201 / 262$ & $206 / 255$ & $211 / 249$ & $223 / 242$ \\
France & $181 / 256$ & $187 / 250$ & $192 / 249$ & $199 / 248$ & $203 / 246$ & $202 / 253$ \\
Greece & $141 / 286$ & $152 / 293$ & $180 / 277$ & $198 / 266$ & $210 / 250$ & \\
Italy & $145 / 254$ & $163 / 258$ & $194 / 251$ & $207 / 251$ & $206 / 248$ & $218 / 249$ \\
Portugal & $111 / 276$ & $150 / 271$ & $166 / 269$ & & & \\
Spain & $98 / 268$ & $116 / 272$ & $136 / 261$ & $165 / 255$ & $184 / 249$ & $199 / 250$ \\
\hline
\end{tabular}

Table 2. Fire-season frequency in different Mediterranean zones. Frequency calculated as the percentage of the no. of fire seasons over $30 \mathrm{yr}$. See Table 1 for elevation classes

\begin{tabular}{|lrrrccc|}
\hline & 1 & 2 & 3 & 4 & 5 & 6 \\
\hline Balkan & 98.1 & 94.9 & 78.1 & 63.0 & 42.4 & 6.7 \\
France & 93.4 & 82.4 & 76.0 & 63.8 & 58.9 & 20.0 \\
Greece & 99.5 & 99.3 & 96.3 & 90.0 & 46.7 & \\
Italy & 99.5 & 94.2 & 69.8 & 39.5 & 23.9 & 9.8 \\
Portugal & 100.0 & 100.0 & 100.0 & & & \\
Spain & 97.8 & 96.8 & 96.3 & 90.0 & 71.7 & 18.3 \\
\hline
\end{tabular}




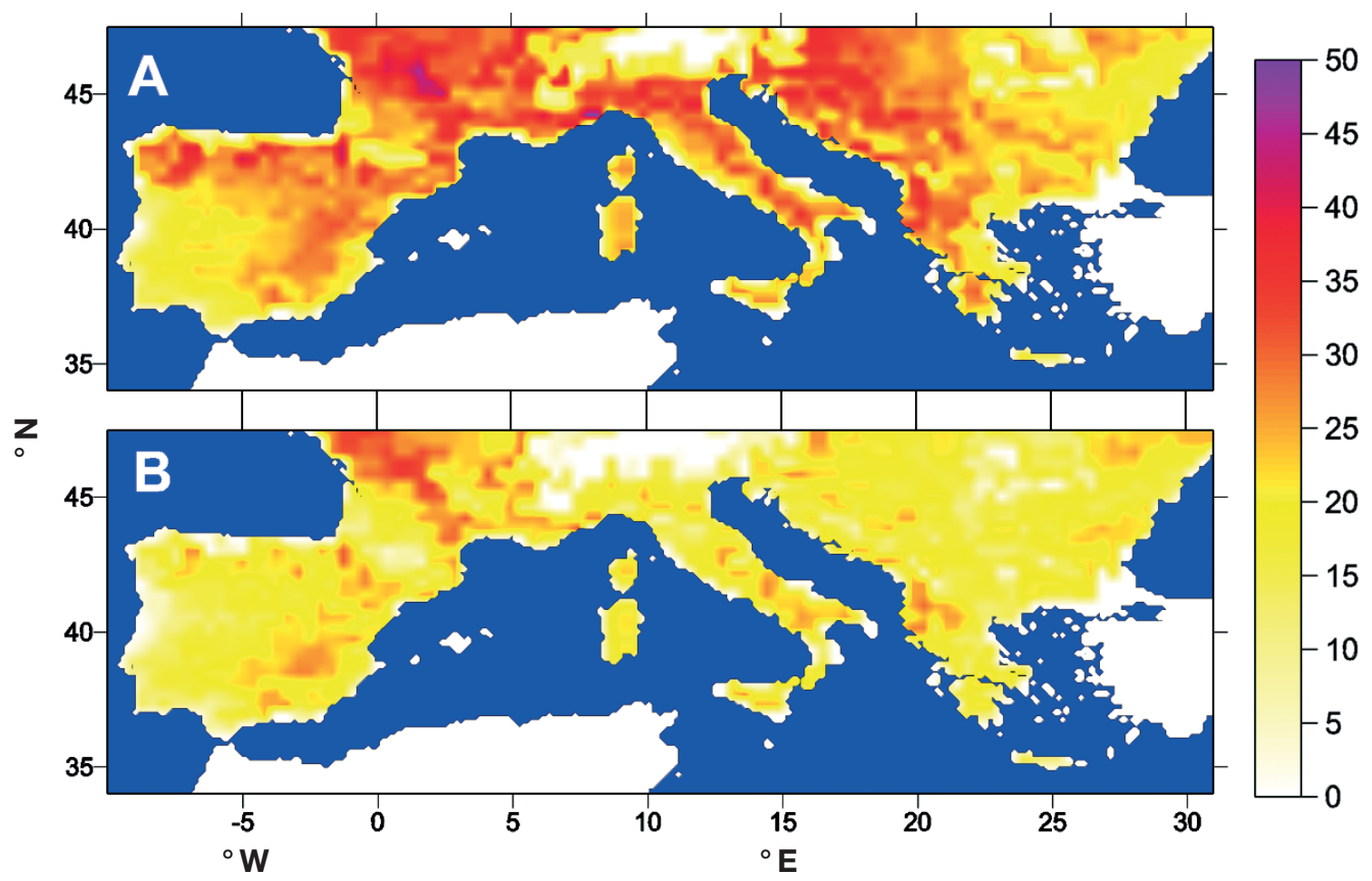

Fig. 3. Percentage changes of mean seasonal FWI for the (A) A2 and (B) B2 scenarios

B2. In other countries, FWI increases ranged from $16 \%$ (Portugal) to $25 \%$ (Italy) in A2 and from 11\% (Portugal) to $18 \%$ (Spain) in B2 (Fig. 4A). When taking elevation into consideration, in general, the highest increases in FWI were observed for elevations ranging from 300 to $900 \mathrm{~m}$ a.s.l. ( 25\% in A2 and $18 \%$ in B2), whereas at the highest elevations (>1500 $\mathrm{m}$ a.s.l.), increases in FWI were less pronounced ( 15\% in A2 and $\sim 1 \%$ in B2) (Fig. 4B). When relating these increases to actual forest cover, the results showed that regions such as central France, the Apennines regions in Italy, and countries of former Yugoslavia-where percent- age of forest cover was rather high (>30\%, Fig. 1)may be strongly affected by these changes in fire risk.

\subsubsection{Number of years with fire risk}

In the whole study area, the number of years with fire risk increased in both future scenarios (Fig. 5). The highest increases in frequency of years with fire risk were observed in the northern and mountainous areas (Fig. 6). In these areas in the present scenario, fire risk is very low and fire seasons infrequent (Fig. 6B). In

Fig. 4. Mean seasonal FWI in present (1961-1990; grey), A2 (2071-2100; white) and B2 (2071-2100; black) scenarios for (A) different countries and (B) elevation classes. See Table 1 for elevation classes
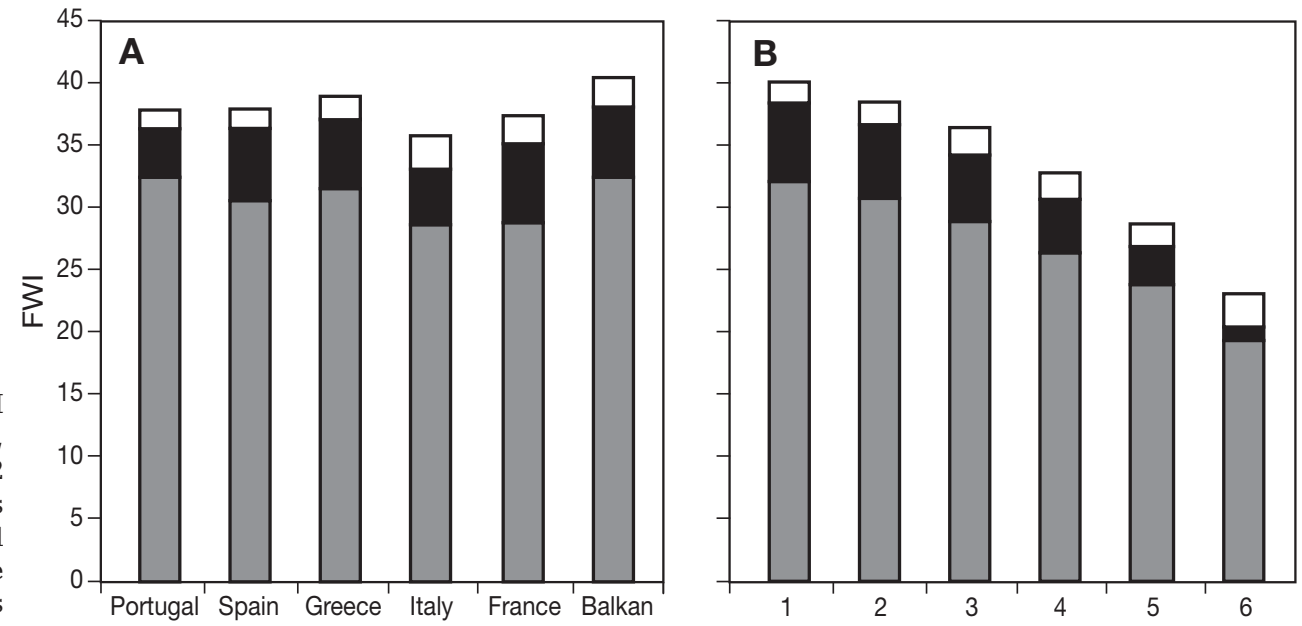


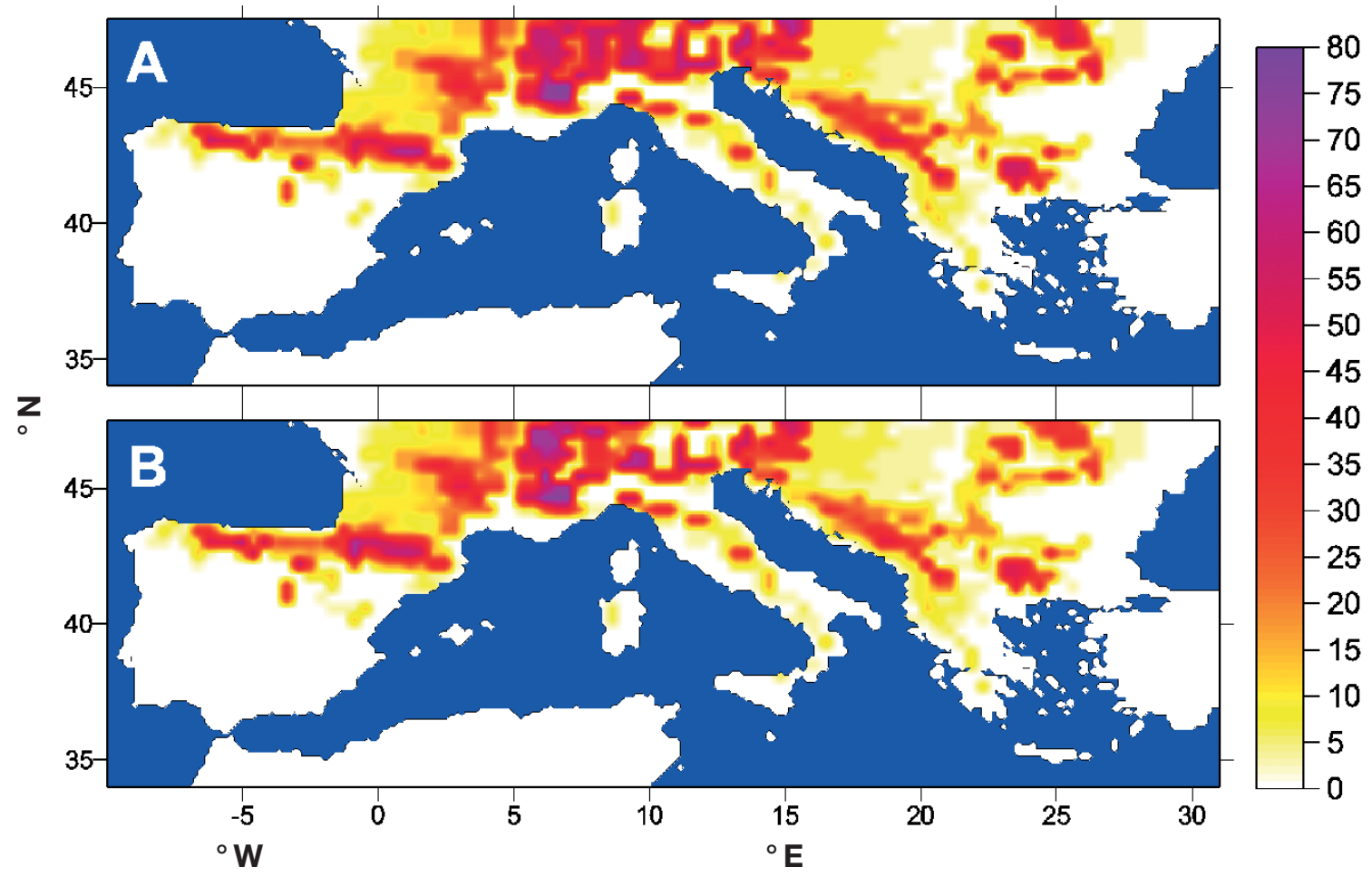

Fig. 5. Percentage changes of no. of seasons with fire risk for the (A) A2 and (B) B2 scenarios

contrast, in the A2 and B2 future scenarios, conditions required for the start of the fire season were more often attained. Principally affected are the Alps region in Italy, the Pyrenees in Spain and mountains of the Balkan region, where forest cover is very high $(>50 \%$, Figs. 1 \& 5). Moreover, the increase was also evident in smaller/less-elevated mountain chains such as the Apennines chain in Italy and the Cantabric mountains in Spain. In contrast, in the flat and southern areas, no or very small changes in the frequency of the years with fire risk was observed, since in these areas the risk of fire was already apparent in the present scenario (Fig. 6).

\subsubsection{Length of fire season}

These increases in seasonal FWI and number of fire seasons were matched by a corresponding increase in fire season length (Fig. 7). In general, for both future scenarios, the beginnings and ends of fire seasons were recorded earlier and later, respectively, than with the present scenario; this was in line with other experiments (Wotton \& Flannigan 1993) (Fig. 8). More specifically, when averaged over the whole Mediterranean basin, the beginning of the fire season was 27 d earlier in A2 and 22 d earlier in B2 in comparison to the present day. The largest changes

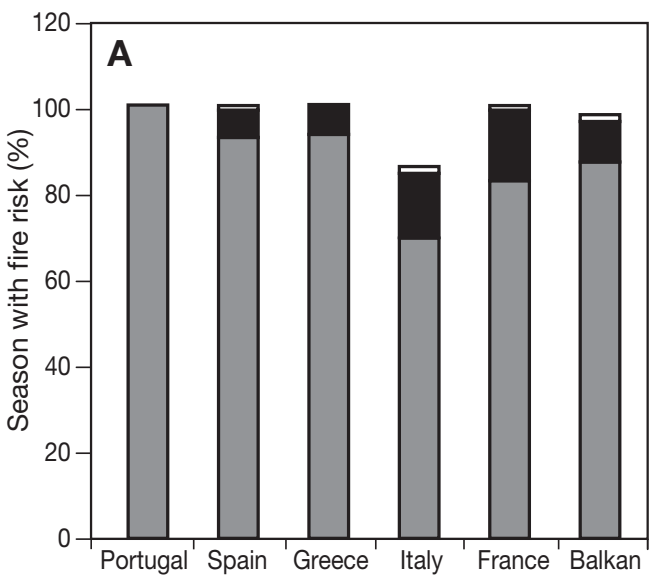

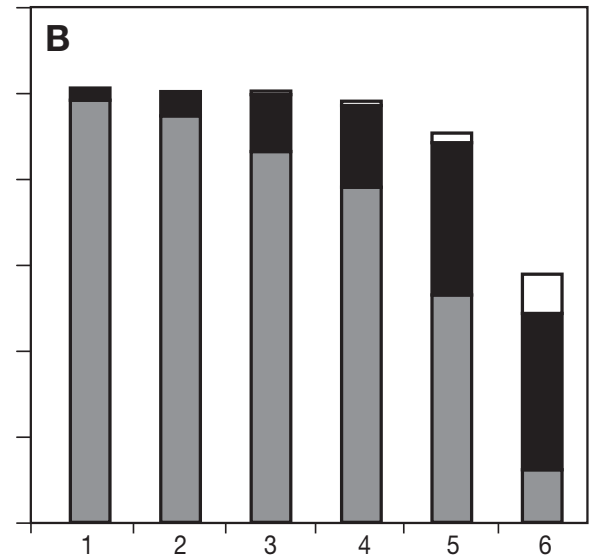

Fig. 6. Percentage of seasons with fire risk in present (1961-1990; grey), A2 (20712100; white) and B2 (20712100; black) scenarios for (A) different countries and (B) elevation classes. See Table 1 for elevation classes 


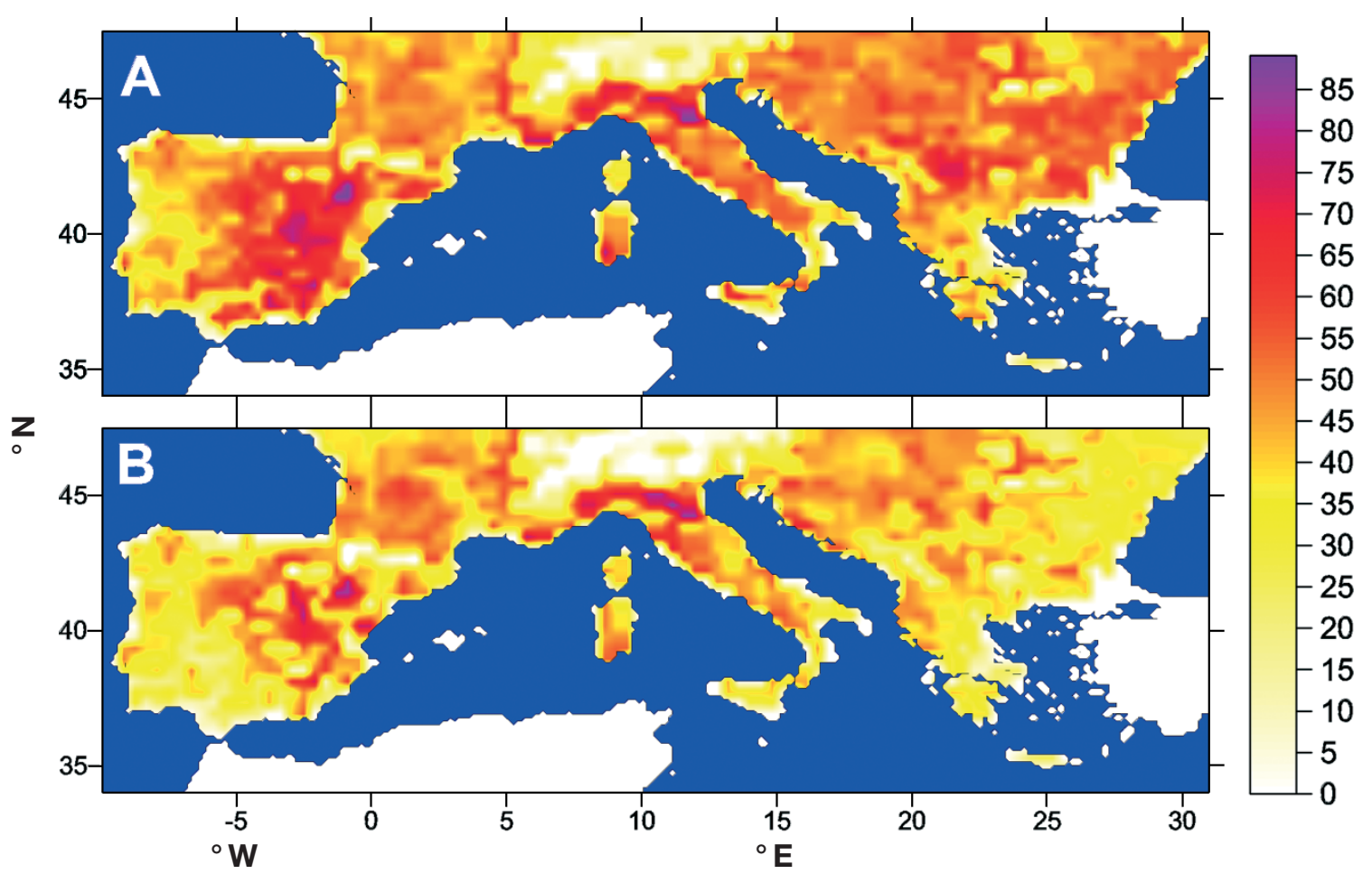

Fig. 7. Absolute changes (no. of days) of the length of seasons with fire risk for the (A) A2 and (B) B2 scenarios

were generally observed in the belt between 600 and $1200 \mathrm{~m}$ a.s.l. (34 and $27 \mathrm{~d}$ earlier in A2 and B2, respectively) (Fig. 8B). For higher altitudes (>1500 m asl), changes to the beginning of the fire season were less evident ( $9 \mathrm{~d}$ in $\mathrm{A} 2$ and $\sim 4 \mathrm{~d}$ in B2). On the other hand, the end of the fire season was on average delayed by 12 and $10 \mathrm{~d}$ in A2 and B2, respectively, with rather large differences apparent among elevation classes (Fig. 8B). Large increases in fire season length were observed especially in the south of Spain (for elevations higher than $900 \mathrm{~m}$ ), in Italy along the west coastline and in the Po valley, and in the Balkan region (Fig. 7). However, these large increases in fire season length may have lesser effects on fire risk, as these were usually localised in areas where the actual forest cover was rather low (>40\%, Fig. 1).

\subsection{Changes in extreme fire-related events}

\subsubsection{Highest annual daily FWI values}

The 100 yr return level of annual maximum daily FWI values calculated by the GEV analysis highlighted a significant and general increase in annual extreme events in both future scenarios (Fig. 9), with large variations, however, within the study area and elevation classes. In particular, the highest percentage increases
Fig. 8. Length of seasons (day of year) with fire risk in present (1961-1990; grey), A2 (2071-2100; white) and B2 (2071-2100; black) scenarios for (A) different countries and (B) elevation classes. See Table 1 for elevation classes

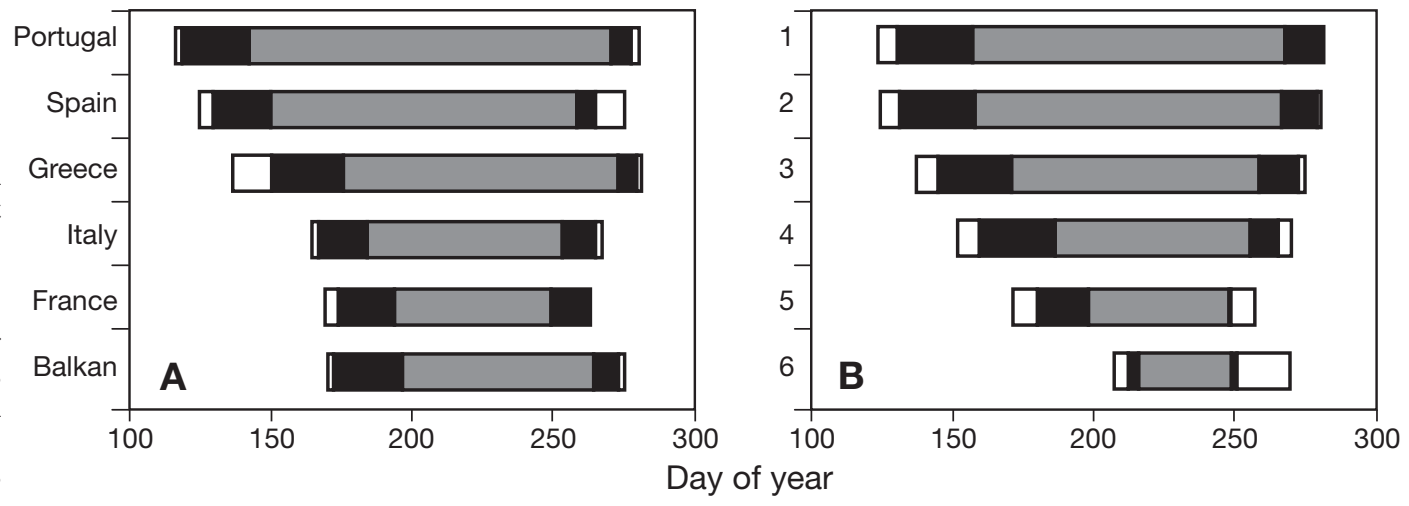




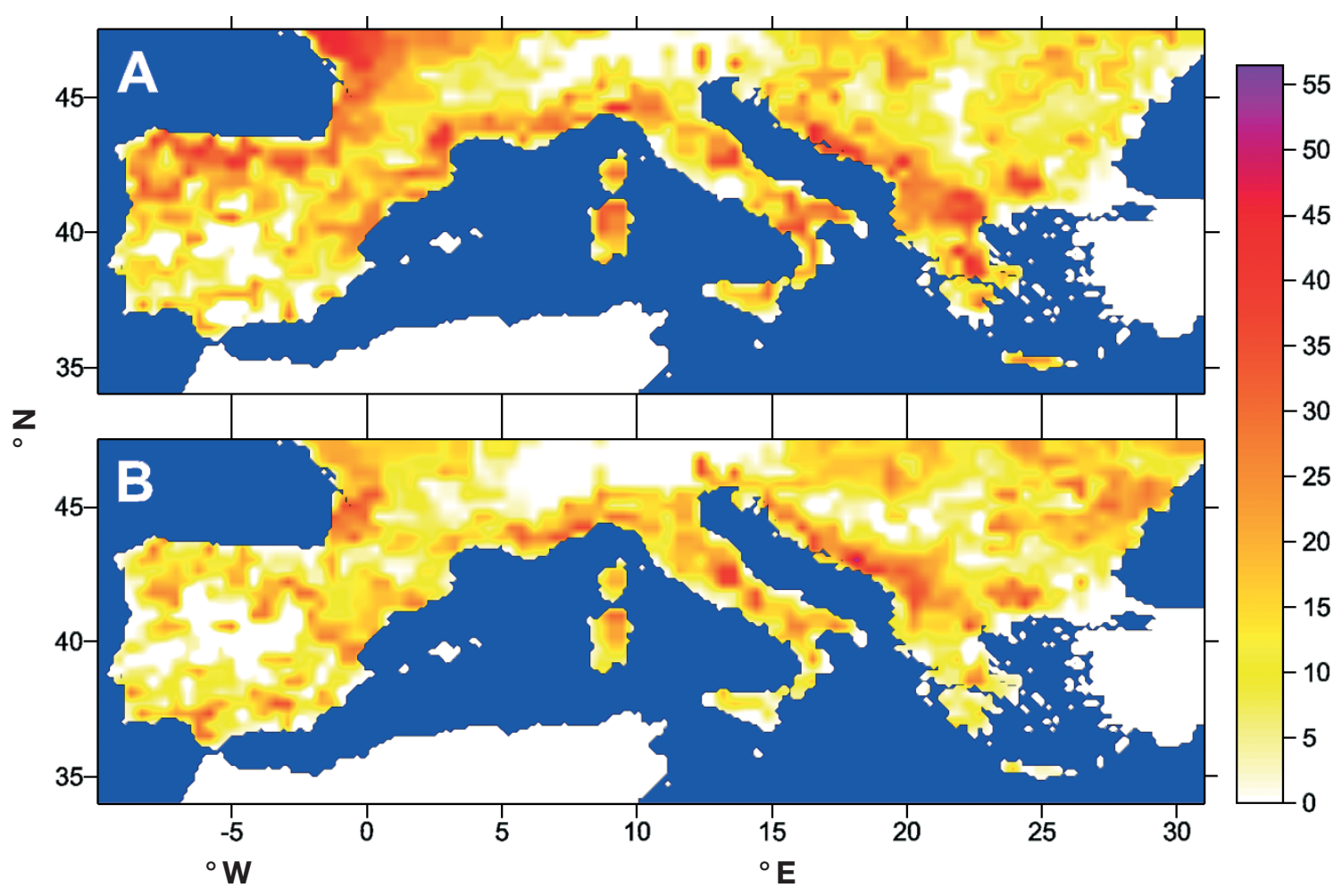

Fig. 9. Percentage changes of maximum daily FWI value calculated for a return period of 100 yr for the (A) A2 and (B) B2 scenarios

were observed in Italy and France, where the $100 \mathrm{yr}$ return level of annual maximum daily FWI increased by 21 and $19 \%$ in $\mathrm{A} 2$ and 14 and $13 \%$ in B2, respectively (Fig. 10A). Within selected elevation classes, the percentage changes were higher in mountainous areas (>1500 $\mathrm{m}$ asl), with increases ranging from the $96 \%$ in the $\mathrm{A} 2$ and $54 \%$ in the B2 scenario (Fig. 10B).

\subsubsection{Total number of daily FWI above a threshold during the fire season}

The whole study area was characterised by a general increase in the number of days with a high fire risk probability. The number of days with FWI $>45$, expressed as a percentage of the total number of days in a fire season, increased throughout the study area and, as expected, the increase was more remarkable in A2 than in B2 (Fig. 11). In the present scenario, the number of days when FWI $>45$ was about $24 \%$, ranging from 18 (Portugal) to $36 \%$ (Balkan region). The highest percentage $(23 \%)$ of FWI $>45$ was observed in flat areas (0 to $300 \mathrm{~m}$ a.s.l.); in contrast, and following a decreasing trend with increasing elevation, lowest values were observed in mountainous areas $(>1500 \mathrm{~m}$ a.s.l.) $(6 \%)$. In the future scenarios, number of events with FWI $>45$ increased on average by 83 (A2) and $55 \%$ (B2). In particular, as observed before, France suffered the largest increase in the number of days of FWI $>45$ (117 and $87 \%$ in A2 and B2) whereas the increase
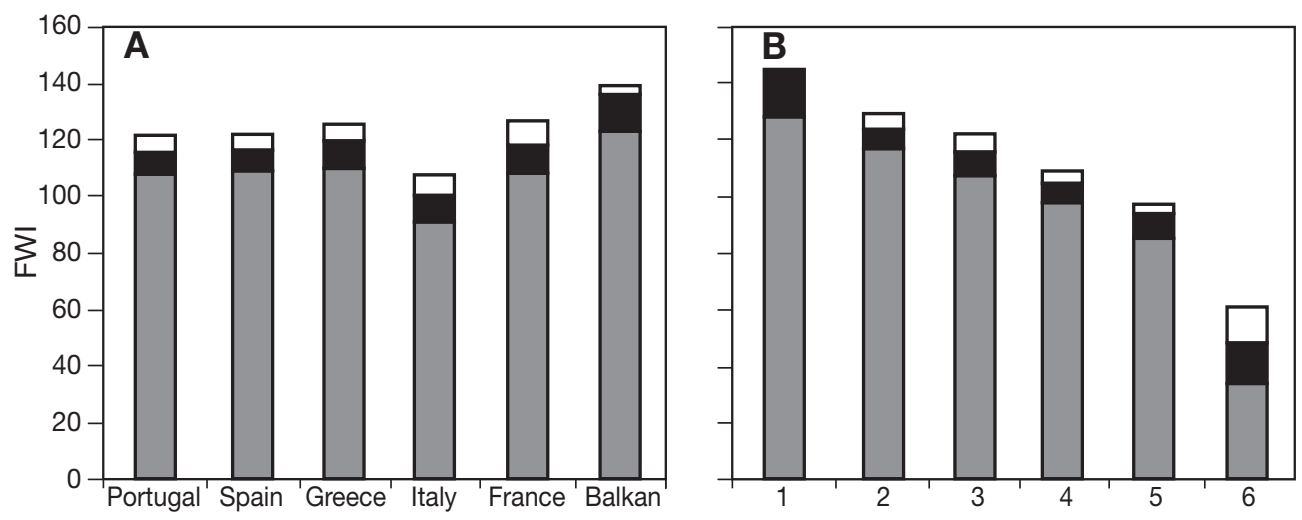

Fig. 10. Maximum daily FWI value calculated for a return period of $100 \mathrm{yr}$ in present (1961-1990; grey), A2 (2071-2100; white) and B2 (2071-2100; black) scenarios for (A) different countries and (B) elevation classes. See Table 1 for elevation classes 


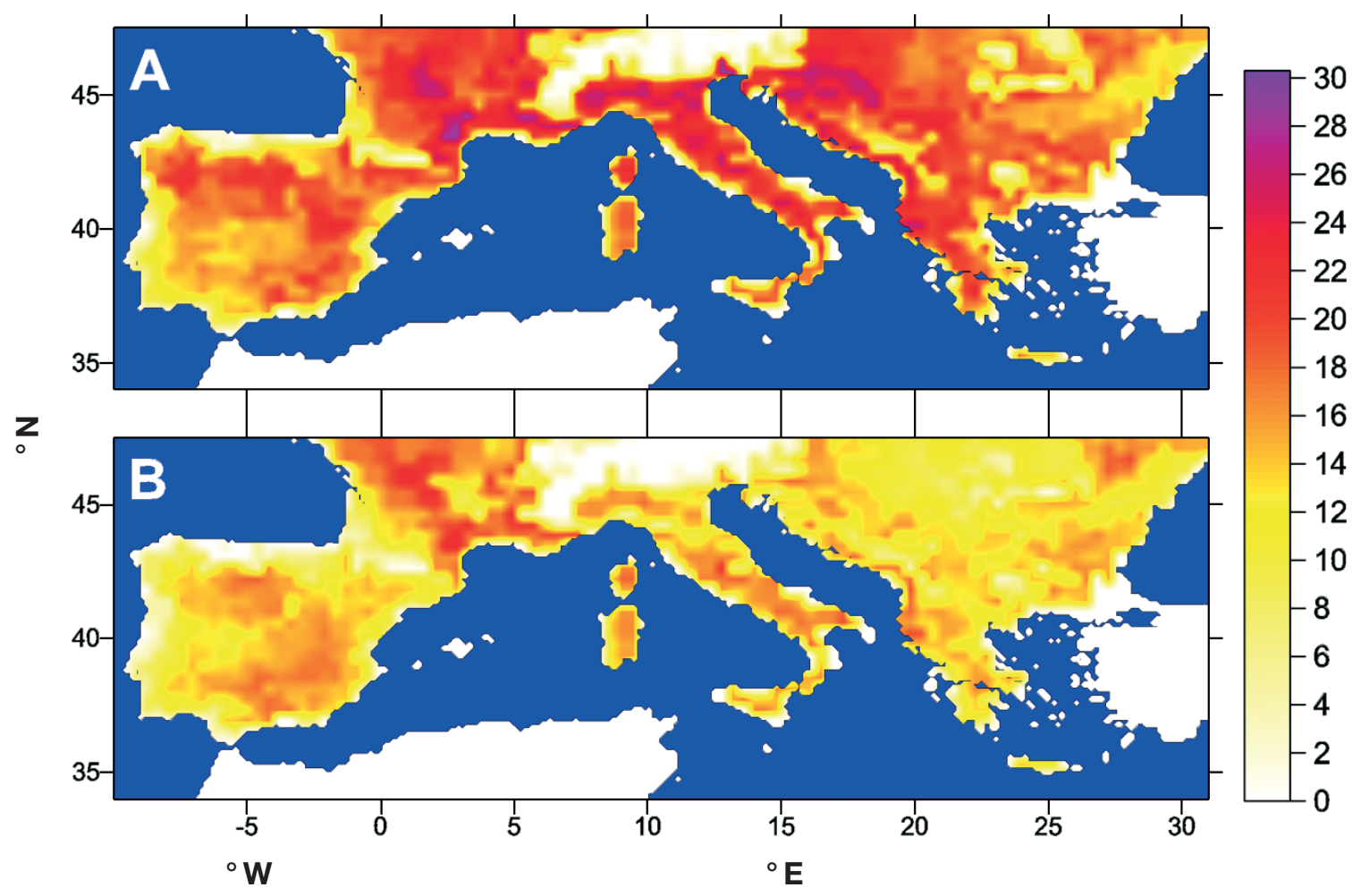

Fig. 11. Percentage changes of no. of days with FWI > 45 for (A) A2 and (B) B2 scenarios

in the other countries ranged from 50 (Portugal) to $104 \%$ (Italy) in A2 and from 35 (Portugal) to 68\% (Italy) in B2 (Fig. 12A). When considering the elevation classes, areas up to $1200 \mathrm{~m}$ a.s.l. showed the highest increases (136 and $94 \%$ in A2 and B2), whereas lesser increases were observed at higher altitudes (51 and $20 \%$ in A2 and B2) (Fig. 12B).

\subsubsection{Persistence of high FWI values during the fire season}

The same trend was observed for the persistence of episodes with FWI $>45$ for at least 7 consecutive days (Fig. 13). The persistence of episodes with high fire risk probability (FWI > 45) generally increased in all study areas, with average increases of 108 and $80 \%$ in A2 and B2, respectively. France was again the country that showed the highest increase in both A2 (174\%) and B2 (127\%). Other countries showed increases ranging from 70 to $136 \%$ (A2) and from 49 to $88 \%$ (B2) (Fig. 14A). Elevation classes from 0 to $1200 \mathrm{~m}$ a.s.l. were also those most affected by climate change (189 and $120 \%$ in A2 and B2, respectively) (Fig. 14B).

\section{CONCLUSIONS}

The 2 RCM future climate scenarios (HadRM3P-A2 and HadRM3P-B2) used in this study suggest a general
Fig. 12. No. of days with FWI $>45$ in present (1961-1990; grey), A2 (2071-2100; white) and B2 (2071-2100; black) scenarios for (A) different countries and (B) elevation classes. See Table 1 for elevation classes
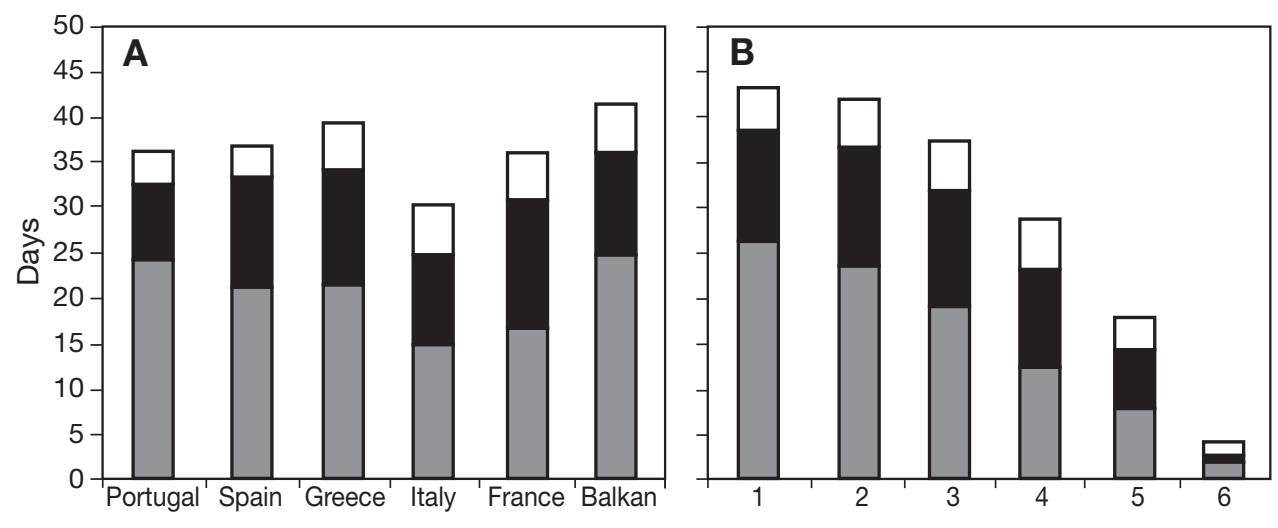


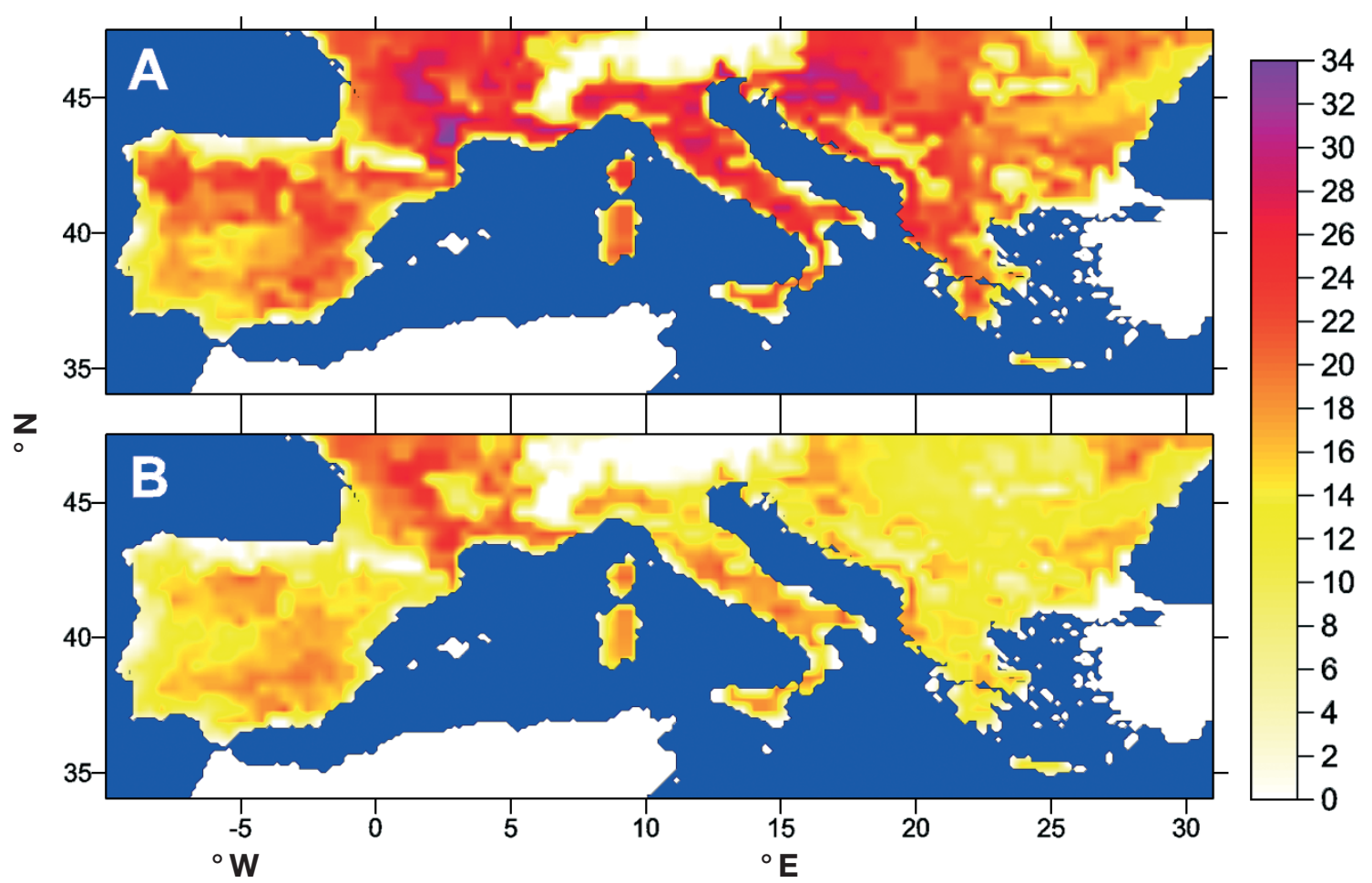

Fig. 13. Percentage changes in the no. of episodes of FWI > 45 for at least 7 consecutive days for (A) A2 and (B) B2 scenarios

increase in fire risk over the Mediterranean countries, with a very strong impact in areas where forest land cover is high (Alps region in Italy, Pyrenees in Spain, and mountains of the Balkan region). More specifically, different characteristics of fire regimes may contribute to these higher risks, such as the increase in the number of seasons with fire risk, the increase in the length of seasons with fire risk, and in particular the increase of extreme events (maximum daily FWI value, total number of days with FWI $>45$, and persistence of episodes with FWI $>45$ for 7 consecutive days). These results are in agreement with those reported by Flannigan et al. (2000) for North America and Williams et al. (2001) for Australia. In all studies, the higher risks in forest fire are direct consequences of increases in maximum temperature and decreases in rainfall and relative humidity during the summer period that favours conditions for forest fire.

The consequences of this impact of climate change on the fire regime in Mediterranean countries could have an almost direct and significant impact on ecosystems, due to likely increases in area burnt and in fire intensity and severity. Manipulations of fuel type, load and arrangement should be used to help protect local areas of high value; however, at a larger scale, fuel management would not be feasible. Additionally, fires
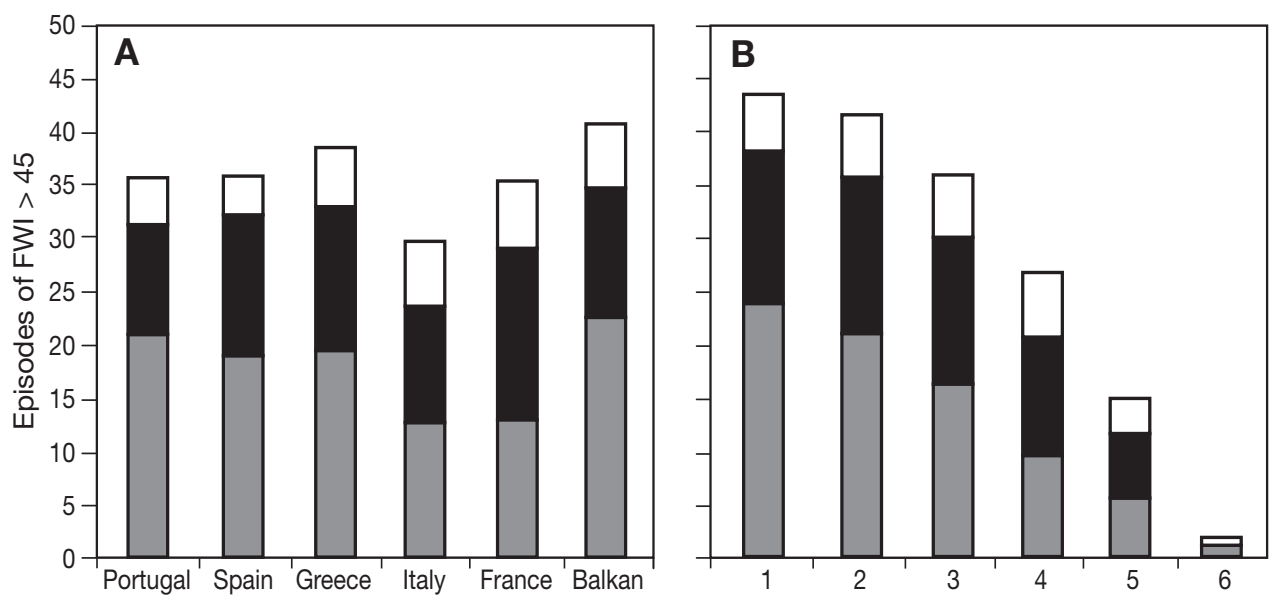

Fig. 14. No. of episodes of FWI $>45$ for at least 7 consecutive days in present (1961-1990; grey), A2 (2071-2100; white) and B2 (2071-2100; black) scenarios for (A) different countries and (B) elevation classes. See Table 1 for elevation classes 
may become increasingly important in terms of determining whether Mediterranean forests are a carbon sink. Thus, continued research is required to further explore relationships between climate change and fire, especially in those areas (e.g. mountain regions) that, in present climatic conditions, are almost unaffected by forest fire risk.

Acknowledgements. This research was supported by the Commission of the EU (Project MICE no. EVK2-CT-200100118).

\section{LITERATURE CITED}

Aguado I, Chuvieco E, Martín P, Salas FJ (2003) Assessment of forest fire danger conditions in southern Spain from NOAA images and meteorological indices. Int J Remote Sens 24:1653-1668

Arnell NW (2003) Effects of climate change on river flows and groundwater recharge using the 477 UKCIP02 scenarios. Report to UK Water Industry Research. University of Southampton, Southampton

Beer T, Gill AM, Moore PHR (1988) Australian bushfire danger under changing climate regimes. In: Pearman GI (ed) Greenhouse: planning for climate change. CSIRO, Melbourne

Brown TJ, Hall BL, Westerling AL (2004) The impact of twenty-first century climate change on wildland fire danger in the western United States: an applications perspective. Clim Change 62:365-388

Clark JS (1990) Fire and climate change during the last $750 \mathrm{yr}$ in northwestern Minnesota. Ecol Monogr 60:135-159

Court-Picon M, Gadbin-Henry C, Guibal F, Roux M (2004) Dendrometry and morphometry of Pinus pinea L. in Lower Provence (France): adaptability and variability of provenances. For Ecol Manage 194:319-333

Dimitrakopoulos A (1994) Analysis of forest fire causes in Greece. Meditteranean Agronomic Institute, Chania

Flannigan MD, Stocks BJ, Wotton BM (2000) Climate change and forest fires. Sci Total Environ 262:221-229

Flannigan M, Campbell I, Wotton M, Carcaillet C, Richard P, Bergeron Y (2001) Future fire in Canada's boreal forest: paleoecology results and general circulation model-regional climate model simulations. Can J For Res 31:854-864

Giorgi F (1990) Simulation of regional climate using a limited area model nested in a general circulation model. J Clim 3:941-963

Hanson CE, Palutikof JP (2005) Final report of Modelling the Impacts of Climate extremes (MICE) Project. Project number: EVK2-CT-2001-00118

Howden SM, Moore JL, McKeon GM, Reyenga PJ, Carter JO, Scanlan JC (1999) Global change impacts on fire dynamics in the mulga woodlands of south-west Queensland. Working Paper Series 99/05. CSIRO Wildlife and Ecology, Canberra, available at www.cse.csiro.au/publications/ 1999/firemulga-99-05.pdf

Hulme M, Jenkins GJ, Lu X, Turnpenny JR and 8 others (2002) Climate change scenarios for the United Kindom: the UKCIP02 scientific report. University of East Anglia, Norwich

Iliadis LS (2004) A decision support system applying an integrated fuzzy model for long-term forest fire risk estimation. Environ Model Softw 20:613-621
IPCC (Intergovernmental Panel on Climate Change) (2000) Special report on emissions scenarios. Cambridge University Press, Cambridge

Kharin VV, Zwiers FW (2000) Changes in the extremes in an ensemble of transient climate simulations with a coupled atmosphere-ocean GCM. J Climate 13:3760-3788

Kurz WA, Apps MJ, Stocks BJ, Volney JA (1995) Global climate change: disturbance regimes and biospheric feedbacks of temperate and boreal forests. In: Woodwell GM, Mackenzie FT (eds) Biotic feedbacks in the global climatic system. Will the warming feed the warming? University Press, New York, p 119-133

Mouillot F, Rambal S, Joffre R (2002) Simulating climate change impacts on fire frequency and vegetation dynamics in a Mediterranean-type ecosystem. Global Change Biol 8:423-437

Pearce HG, Mullan AB, Salinger MJ, Opperman TW, Woods D, Moore JR (2005) Impact of climate change on longterm fire danger, NIWA Client Report: AKL2005-45. New Zealand Fire Service Commission, Wellington, available at www.fire.org.nz/research/reports/reports/Report_50.htm

Schuck A, Van Brusselen J, Päivinen R, Häme T, Kennedy P, Folving S (2002) Compilation of a calibrated European forest map derived from NOAA-AVHRR data. EFI Internal Report 13, European Forest Institute, Joensuu

Simard AJ, Eenigenburg JE, Main WA (1989) A weatherbased fire season model. In: MacIver DC, Auld H, Whitewood R (eds) Proc 10th Conf Fire For Meteorol, April 17-21, Ottawa

Sol B (1999) A European program improves the operational fight against forest fires: MINERVE Program and meteorological fire danger in southeastern France. DELFI Proceedings, Athens, p 185-192

Stocks BJ, Fosberg MA, Lynham TJ, Mearns L and 7 others (1998) Climate change and forest fire potential in Russian and Canadian boreal forests. Clim Change 38:1-13

Torn MS, Fried JS (1992) Predicting the impacts of global warming on wildland fire. Clim Change 21:257-274

Turner JA, Lawson BD (1978) Weather in the Canadian forest fire danger rating system: a user guide to national standards and practices, Rep BC-X-177. Environment Can, Victoria, BC

Van Wagner CE (1975) A comparison of the Canadian and American forest fire danger rating system, Rep PS-X-59. Canadian Forest Service, Chalk River, ON

Van Wagner CE (1987) Development and structure of a Canadian forest fire weather index system, Forestry Technical Report 35. Canadian Forestry Service, Ottawa

Velez R (1997) Recent history of forest fires in the Mediterranean area. In: Peter D, Maracchi G, Ghazi A (eds) Proc Eur School Climatol Natural Hazards Course. European Commission, Luxembourg

Viegas DX, Biovio G, Ferreira A, Nosenzo A, Sol B (1999) Comparative study of various methods of fire danger evaluation in southern Europe. Int J Wildland Fire 10: 235-246

Viegas DX, Piñol J, Viegas MT, Ogaya R (2001) Estimating live fine fuels moisture content using meteorologicallybased indices. Int J Wildland Fire 10:223-240

Whelan RJ (1995) The ecology of fire. Cambridge University Press, Cambridge

Williams AAJ, Karoly DJ, Tapper N (2001) The sensitivity of Australian fire danger to climate change. Clim Change 49:171-191

Wotton BM, Flannigan MD (1993) Length of the fire season in a changing climate. For Chronol 69:187-191 